\title{
Tylophorine: Sources, Properties, Applications and Biotechnological Production
}

\author{
Angeline Cyriac, Toji Thomas, and T. Dennis Thomas
}

\section{Introduction}

Tylophora indica (Burm. f.) Merr. resides in Asclepiadaceae of angiosperm family. The plant is a curative climber originally established in the plain and hilly areas of forest found in the Eastern and Southern India extending to an elevation of $900 \mathrm{~m}$. Various synonyms of the plant include Cynanchum indicum Burm. f., T. asthmatica (L. f.) Wight and Arn. in Wight, Asclepias asthmatica L. f. and A. prolifera Rottl. ex Ainslie. Its common English name is 'emetic swallow-wort' (Sasidharan 2004). Due to its excessive medicinal use, attempts were made to standardize micropropagation protocols in this plant by using different explants (Thomas and Philip 2005; Thomas 2006, 2009). Plant secondary metabolites are chemical compounds having negligible function in the perpetuation of fundamental life activities in plants which manufacture it. However, it has crucial task in the intercommunication of the plant with its habitat. The synthesis of these compounds is usually a little (less than $1 \%$ dry weight), and it has tremendous influence on the physiological and developmental state of the plant (Dixon 2001; Oksman-Caldentey and Inzé 2004). The major alkaloid present in T. indica is phenanthroindolizidine type, and its heterocyclic ring consists of indolizidine ring fused to a phenanthrene ring. This alkaloid was isolated and named as 'tylophorine' by Ratnagiriswaran and Venkatachalam (1935) for the first time. Along with tylophorine, they had isolated alkaloid 'tylophorinine' also from the aerial parts of T. indica. The roots and foliage of the plant yield $0.2-0.46 \%$ tylophorine, tylophorinine and tylophrinidine (Gopalakrishnan et al. 1979). The plant is conventionally employed for the medication of several respiratory disorders such as bronchitis, seasonal cough and cold, hay fever and asthma (Haranath and Shayamalakumari 1975; Gupta et al. 1979; Rao et al. 1980). The roots along with

\author{
A. Cyriac · T. Thomas \\ Department of Botany, St. Thomas College Palai, Pala, Kerala, India \\ T. D. Thomas $(\triangle)$ \\ Department of Plant Science, Central University of Kerala, Kasaragod, Kerala, India
}


leaves of the plant are further employed to alleviate jaundice and liver disorders (Devprakash et al. 2012). Tylophorinine, a minor alkaloid, was isolated and characterized from T. asthmatica by Govindachari et al. (1961). Dhiman et al. (2013) isolated and characterized a novel phenanthroindolizidine alkaloid, 3-O-demethyl tylophorinidine (VI), from the leaves and stems of $T$. indica by utilizing various chromatographic and spectroscopic techniques. Zhen et al. (2002) reported that phenanthroindolizidine alkaloids like tylophoridicine A, $O$-methyl tylophorinidine and tylophorinidine possessed prominent anticancer activity towards different cell lines.

\section{Sources and Chemistry of Tylophorine}

Ratnagiriswaran and Venkatachalam (1935) separated and quantified tylophorine and tylophorinine from $T$. asthmatica (syn. T. indica). These compounds were segregated through fractional crystallization of the composite salts. Rao and Brook (1970) extracted biologically efficacious alkaloids including tylophorine from $T$. indica and T. dalzellii by acid extraction succeeded by solvent distillation utilizing methanol followed by ethyl acetate and chloroform. Viswanathan and Pai (1985) analysed the chemical constituents in T. mollissima and isolated caffeine alkaloid as a greater constituent, along with tylophorine and tylophorinine, a lesser content alkaloids. The compounds were characterized by different spectroscopic techniques. Govindachari (2002) separated and quantified tylophorinidine, tylophorine, tylophorinine, septicine and isotylocrebrine by chromatographic method utilizing alumina. They had reviewed the structure of tylophorinine and tylophorinidine through X-ray scrutiny. It is believed that the presence of several alkaloids including tylophorine in the form of secondary metabolites in Tylophora resulted in its high medicinal value in herbal medicine.

Tylophorine $\left(\mathrm{C}_{24} \mathrm{H}_{27} \mathrm{NO}_{4}\right)$ is a bioactive secondary metabolite present in $T$. indica (Fig. 1). It contains organonitrogen heterocyclic and organic heteropentacyclic compounds. Its IUPAC name is (13as)-2,3,6,7-tetramethoxy-9,11,12,13,13a,14hexahydrophenanthro[9,10-f] indolizine. It has a tertiary base with a 2,3,6,7-methoxylsubstituted phenanthrene ring system and is joined with an indolizidine ring in its 9,10-position. The molecular formula of this compound is $\mathrm{C}_{24} \mathrm{H}_{27} \mathrm{NO}_{4}$. The molecular

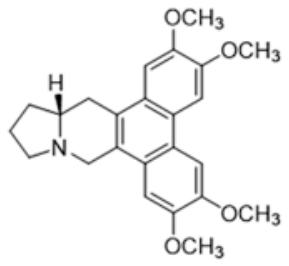

Tylophorine

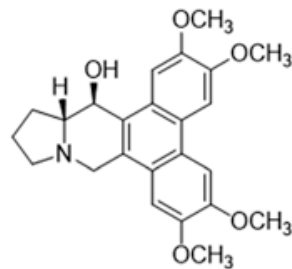

Tylophorinine

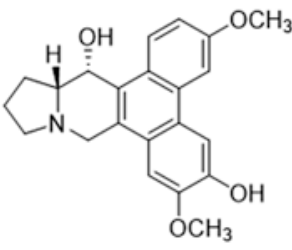

Tylophorinidine

Fig. 1 Chemical structures of prominent alkaloids from Tylophora indica 
weight of tylophorine is $393.194008 \mathrm{~g} / \mathrm{mol}$. Elemental analysis showed C $73.26 \%, \mathrm{H}$ $6.92 \%, \mathrm{~N} 3.56 \%$ and $\mathrm{O} 16.26 \%$ as the percentage composition of various elements (Ali and Butani 1989). The related compounds include tylophorinine and tylophrinidine (Fig. 1).

The IUPAC name of tylophorinine $\left(\mathrm{C}_{23} \mathrm{H}_{25} \mathrm{NO}_{4}\right)$ compound is $(13 a S, 14 R)-3,6,7-$ trimethoxy-9, 11, 12, 13, 13a, 14-hexahydrophenanthro [9, 10-f] indolizin-14-ol. The molecular weight of tylophorinine is $379.400 \mathrm{~g} / \mathrm{mol}$ (Mulchandani et al. 1971). The IUPAC name of tylophrinidine $\left(\mathrm{C}_{22} \mathrm{H}_{22} \mathrm{NO}_{4}\right)$ is (13aS,14S)-3,7-dimethoxy-9, $11,12,13,13 a$, 14-hexahydrophenanthro [10, 9-f] indolizine-6, 14-diol, and the molecular weight is $365.4 \mathrm{~g} / \mathrm{mol}$ (Mulchandani et al. 1971).

\section{Bioactive Properties and Application of Tylophorine}

Family Asclepiadaceae produces phenanthroindolizidine alkaloids as major secondary metabolites. The phenanthroindolizidine alkaloids are considered as extremely important phytochemical due to its intense cytotoxic effect. This is due to its role in the prevention of the synthesis of DNA and proteins (Rao et al. 1997, 1998; Abe et al. 1998; Rao and Venkatachalam 2000). The properties and bioactivities of tylophorine has been well investigated (Table 1). Tylophorine possesses antiproliferative action in cancer cells; it rapidly diminishes cyclin D1, reduces protein biosynthesis and prevents vascular smooth muscle cell proliferation in vitro (Joa et al. 2019). Apoptosis could be mediated by unique application of tylophorine or tylophorine plus doxorubicin in T47D breast cancer cells; this happened because it regulated the expression of genes of caspases 3 and 9 (Pratama et al. 2018). Wang et al. (2017) communicated that tylophorine analogues like DCB-3503 and raccryptopleurine could interrupt hepatitis $\mathrm{C}$ virus multiplication. The tylophorineassisted downregulation of cyclin A2 protein levels resulted in primary G1 arrest. Chromatin immunoprecipitation studies disclosed that tylophorine induced c-Jun downregulation of the cyclin A2 promoter activity (Yang et al. 2013). Tylophorine could induce anti-angiogenesis effects via VEGFR2 signalling pathway and acts as a suitable drug candidate for anti-angiogenesis and anticancer therapies (Saraswati et al. 2013). According to Niphakis et al. (2012), tylophorine alkaloid has remarkable antiproliferative properties. The efficiency of tylophorine compounds as a unique and vigorous anti-coronavirus factor as well as the probability to develop it into therapeutic agents for alleviating transmittable gastroenteritis virus (TGEV) or severe acute respiratory syndrome coronavirus (SARS CoV) infection has been reported by Yang et al. (2010).

DCB-3503 is an analogue of tylophorine; it arrests the multiplication of PANC-1 (human pancreatic ductal cancer cell line) and HepG2 (human hepatocellular cancer cell line) tumour found in mice. The mechanism of action of inhibition is cell differentiation, and there is no cell death. Nevertheless, the exact role played by tylophorine analogue is obscure. Tylophorine analogue, DCB-3503, can repress translation, and therefore the mode of functioning is dissimilar with other available anticancer molecules as it interferes with protein synthesis (Wang et al. 2010a). In another study conducted by Wang et al. (2010b), several C9-substituted phenanthrene-based 
Table 1 A brief summary of various in vitro bioactivity studies of tylophorine

\begin{tabular}{l|l}
\hline $\begin{array}{l}\text { Biological activity of } \\
\text { tylophorine }\end{array}$ & References \\
\hline $\begin{array}{l}\text { Antiproliferative action in } \\
\text { cancer cells }\end{array}$ & Joa et al. (2019) \\
\hline Anticancer activity & $\begin{array}{l}\text { Pratama et al. (2018); Yang et al. (2013); Saraswati et al. (2013); } \\
\text { Niphakis et al. (2012); Wang et al. (2010b); Wei et al. (2006) }\end{array}$ \\
\hline Anti-inflammatory action & Lee et al. (2011); Yang et al. (2009a); Wen et al. (2014) \\
\hline Cytotoxic activity & Yang et al. (2009b) \\
\hline $\begin{array}{l}\text { Positive stimulant to adrenal } \\
\text { cortex }\end{array}$ & Udupa et al. (1991) \\
\hline Antifeedant activity & Reddy et al. (2009) \\
\hline Antiviral activities & Wang et al. (2010a); Yang et al. (2010); Wang et al. (2017) \\
\hline Antibacterial & Reddy et al. (2009) \\
\hline Antiamoebic action & Bhutani et al. (1985) \\
\hline Antifungal & Reddy et al. (2009) \\
\hline Hepatoprotective activity & Gujrati et al. (2007) \\
\hline Anti-allergic activity & Nayampalli and Sheth (1979); Ganguly et al. (2001) \\
\hline Anti-angiogenic & Saraswati et al. (2013) \\
\hline Diuretic activity & Meera et al. (2009) \\
\hline $\begin{array}{l}\text { Inhibition of cellular } \\
\text { immune responses }\end{array}$ & Ganguly and Sainis (2001) \\
\hline $\begin{array}{l}\text { Therapeutic agent for } \\
\text { inflammatory arthritis }\end{array}$ & You et al. (2006) \\
\hline
\end{tabular}

tylophorine derivatives were made in the lab and evaluated its antiviral properties towards tobacco mosaic virus (TMV). The properties of synthesized compounds were comparable to that of the alkaloid tylophorine. Yang et al. (2009a) observed potent cytotoxic activity for new nine-substituted phenanthrene-based tylophorine analogues. Tylophorine exhibited higher antifeedant activity as compared to septicine, O-methyl tylophorinidine and simple aliphatic acid, isolated from $T$. indica. These pure compounds showed prominent antibacterial action at lower concentrations to several bacterial strains tested other than E. coli. At the same time, pure compounds demonstrated antifungal action against Aspergillus niger, A. fumigatus and Trichoderma viride (Reddy et al. 2009). Tylophorine can provide positive stimulant to adrenal cortex (Udupa et al. 1991). According to Bhutani et al. (1985), tylophorine exhibits antiamoebic action. Hepatoprotective activity was demonstrated in alcoholic and aqueous distillate of $T$. indica foliages, which contained tylophorine (Gujrati et al. 2007). Anti-allergic activity was demonstrated for tylophorine and other related alkaloids. This action is mainly due to immunosuppressive effects, direct bronchodilator and membrane stabilizing properties (Nayampalli and Sheth 1979). Aqueous as well as alcoholic leaf extracts of $T$. indica revealed prominent diuretic action (Meera et al. 2009). Tylophora alkaloids suppressed contact sensitivity towards dinitrofluorobenzene in mice as it was treated just before or after contact sensitization (Ganguly et al. 2001). Anti-inflammatory activity was reported by phenanthroindolizidine alkaloids, such as tylophorine and ficuseptine A (Yang et al. 2009a). 


\section{Biotechnological Production of Tylophorine}

\subsection{Agrobacterium-Mediated Transformation and Tylophorine Production}

The Gram-negative bacterium Agrobacterium rhizogenes is usually present in soil which can infect higher plants and produce genetically modified roots. During transformation, the bacteria transfers T-DNA - a 25-bp oligonucleotide repeatfrom its root inducing $(\mathrm{Ri})$ plasmid to the genome of the affected plant. During this process, the plant can produce fine hair-like roots known as 'hairy roots' at the location of infective spot. This protocol is regarded as one of the most feasible ways of producing useful secondary metabolites without destroying the natural plants. It can provide continuous supply of desired secondary metabolites within a brief period. Chaudhuri et al. (2005) standardized a technique for the transgenic root production in T. indica using A. rhizogenes (LBA 9402 and A4 strains). A. rhizogenes were used to infect the leaves, stems and intact shoots, and calli and roots were induced from such explants at various sites. The response was mainly depending on factors like type of strains used, type explant and the infection sites. Only one strain (i.e. A4) responded and induced transformation. The maximum frequency of transformation was $60 \%$ with intact shoots. The transformed nature of the roots was confirmed by PCR analysis. The tylophorine production varied considerably in various root clones analysed. Roots attained maximum biomass and tylophorine yield in 4-6 weeks of suspension culture. The tylophorine extraction was performed by the modified method of Abe et al. (1995). Roots were dried, powdered and defatted with petroleum ether for $24 \mathrm{~h}$. Further extraction was carried out by using $25-\mathrm{mL}$ chloroform by cold percolation for $24 \mathrm{~h}$. This was performed thrice, and all the extracts were combined and dried by evaporation. The $5-\mathrm{mL}$ residual medium was extracted thrice using chloroform $(10 \mathrm{~mL})$ by continuous stirring for about $2 \mathrm{~h}$, and the chloroform portions were isolated by a separating funnel. All the fractions were pooled together, dried and resuspended in a 5-mL mobile phase and filtered using a millipore filter $(0.2 \mathrm{~mm})$. High-performance liquid chromatography (HPLC) analysis of the transformed roots was performed, and the maximum tylophorine yield was obtained in clone numbers 5 and $41(1.29 \pm 0.02$ and $1.29 \pm 0.5 \mathrm{mg} / \mathrm{g} \mathrm{DW})$, respectively.

\subsection{Extraction from Dried Leaves, Callus and Suspension Cultures}

Anand et al. (2012) isolated tylophorine from the leaves, callus and suspension cultures of Tylophora spp. The protocol employed was cold extraction with acetic acid in methanol, followed by acid extraction with acetic ethyl acetate. Leaf-derived callus (1.0 g) was maintained in MS medium (about $100 \mathrm{~mL}$ ) containing plant growth regulators in a $250-\mathrm{mL}$ conical flask and placed on a shaker with $120 \mathrm{rpm}$. The biomass observations were done every 3 days. The leaves collected from 
field-grown plants were dried and ground to fine powder before processing. The protocol was employed by Rao and Brook (1970) for further processing. Further, extraction protocol employed was cold extraction with acetic acid in methanol, followed by acid extraction with ethyl acetate and $\mathrm{HCl}$. High-performance thin-layer chromatography (HPTLC) technique was used to separate tylophorine, and the samples were confirmed with the presence of tylophorine in comparison with the $\mathrm{Rf}$ value of test samples as that of standard. The outcome of HPTLC result indicated seven dissimilar peaks, of which the seventh one is confirmed as tylophorine. The quantitative analysis was done by analysing the peak area and standard concentration. Of the three different sources employed for quantitative analysis of tylophorine, leaf extract exhibited maximum (yield $80 \mu \mathrm{g} / \mathrm{mL}$ ), followed by leaf callus (yield $24.46 \mu \mathrm{g} / \mathrm{mL}$ ) and suspension extract $(28.30 \mu \mathrm{g} / \mathrm{mL})$. In another similar work by the same authors, Kaur et al. (2011) studied the tylophorine content in leaves of T. indica. The collected foliage was washed in free-flowing tap water. Further, leaves were dried and ground to clear powder using a mortar and pestle. To remove the oil-soluble components, the leaf powder was washed twice with hexane. Further, to extract components in the acetate layer, it was soaked overnight in ethyl acetate. The $\mathrm{pH}$ of the filtered extract was maintained at 3-4 with $\mathrm{HCl}$. Distilled water $(100 \mathrm{~mL})$ was added to dilute the extract and then concentrate it to half of its volume by using a flash evaporator at 55-60 ${ }^{\circ} \mathrm{C}$. Dichloromethane was used to wash the extract three times, and the $\mathrm{pH}$ was adjusted from 11 to 13 by using $\mathrm{NaOH}$. Flash evaporator was used to concentrate the extract and was resuspended in chloroform for HPTLC analysis. With the help of a $100-\mu \mathrm{L}$ syringe, the plant extract was applied on precoated silica gel plates $(10 \times 10 \mathrm{~cm})$ with a band length of $8 \mathrm{~mm}$ and a track separation of $12 \mathrm{~mm}$. Toluene/chloroform/ethanol/ammonia (4:3.5:1.5 drop) was used as solvent system and scanned at $258-\mathrm{nm}$ wave length. The quantitate estimationd of tylophorine was gone by the following formy of standard / Area of standard peak

Densitometry evaluation at $258 \mathrm{~nm}$ showed seven different bands including tylophorine with $\mathrm{Rf} 0.68$ and $81.42 \%$ area. The quantitative estimation showed a yield of $80 \mu \mathrm{g} / \mathrm{mL}$ tylophorine.

\subsection{Extraction Using Maceration Method}

Gupta et al. (2012) developed an experimental procedure for the extraction of tylophorine. This protocol is called maceration method. The extraction experiments were carried out by using various solvents like ethanol (95\%), chloroform and sulphuric acid (2\%). Hot extraction was carried out with $95 \%$ alcohol with various concentrations of glacial acetic acid and citric acid. The defatting of the sample was carried out with petroleum ether and subsequently macerated with $95 \%$ alcohol. 
The extract thus obtained was concentrated to one-fourth volume by using a rotary vacuum evaporator. Further purification was done by acid-base purification technique. Both alkaloid and standard were compared by thin-layer chromatography in order to confirm the presence of tylophorine. The alkaloid tylophorine was characterized by using various techniques like IR, UV, NMR and mass spectroscopy. The alkaloid was further examined by HPLC technique to find out its tylophorine content. Of the various techniques used for tylophorine extraction, hot extraction with $95 \%$ alcohol containing $2 \%$ citric acid gave the best yield. Here the total alkaloid content, tylophorine content and total tylophorine yield were $0.280 \mathrm{~g}, 17.25(\% \mathrm{w} / \mathrm{w})$ and $0.0483 \mathrm{~g}$, respectively. The reason for highest yield in this treatment was due to the reaction of alkaloids with acid and the subsequent formation of salts which is more soluble in $95 \%$ alcohol, and therefore higher yield was obtained. Therefore, it was concluded that this protocol is most effective and could be used for the commercial extraction of tylophorine.

\section{Conclusions}

Tylophorine is an alkaloid obtained from $T$. indica. In addition, the plant contains tylophorinine, tylophrinidine, septicine and isotylocrebrine. Major alkaloid tylophorine possesses many properties including immunosuppressive, antitumour, antifeedant, antibacterial, antifungal, antiamoebic, diuretic and hepatoprotective activities. As an important alkaloid, it has different potential medical applications. Although various methods have been standardized for the biotechnological production and extraction of tylophorine, an efficient and cost-effective protocol still needs to be standardized. Moreover, the quantitative improvement of tylophorine still remains as a challenge.

\section{References}

Abe F, Iwase Y, Yamauchi T, Honda K, Hayashi N (1995) Phenanthroindolizidine alkaloids from Tylophora tanakae. Phytochemistry 39:695-699

Abe F, Hirokawa M, Yamauchi T, Honda K, Hayashi N, Ishii M, Imagawa S, Iwahana M (1998) Further investigation of phenanthroindolizidine alkaloids from Tylophora tanakae. Chem Pharm Bull 46:767-769

Ali M, Butani KK (1989) Alkaloids from Tylophora indica. Phytochemistry 28:3513-3517

Anand M, Kaur H, Goyal D (2012) A micropropagation system for Tylophora Indica and extraction and purification of tylophorine from cultures and in vitro regenerated plants. In: International conference on environmental, biomedical and biotechnology, IACSIT Press, Singapore, pp 14-17

Bhutani KK, Sharma GL, Sarin AN, Kaur R, Kumar V, Atal CK (1985) In vitro amoebicidal and bactericidal activities in medicinal plants. Indian J Pharm Sci 47:65-67

Chaudhuri KN, Ghosh B, Tepfer D, Jha S (2005) The root: a potential new source of competent cells for high-frequency regeneration in Tylophora indica. Plant Cell Rep 24:25-35

Devprakash SG, Senthilkumar GP, Tembare R, Mani T (2012) GC-MS analysis of Tylophora indica. Int J Pharm Res Dev 4:222-224 
Dhiman M, Khanna A, Manju SL (2013) A new phenanthroindolizidine alkaloid from Tylophora indica. Chem Pap 67:245-248

Dixon RA (2001) Natural products and plant disease resistance. Nature 411:843-847

Ganguly T, Sainis KB (2001) Inhibition of cellular immune responses by Tylophora indica in experimental models. Phytomedicine 8:348-355

Ganguly T, Badheka LP, Sainis KB (2001) Immunomodulatory effect of Tylophora indica on Con A induced lymphoproliferation. Phytomedicine 8:431-437

Gopalakrishnan C, Shankaranarayan D, Kameswaran L, Natarajan S (1979) Pharmacological investigations of tylophorine, the major alkaloid of Tylophora indica. Indian J Med Res 69:513-520

Govindachari TR (2002) Five decades in the study of natural products. Proc Indian Acad Sci (Chem Sci) 114:175-195

Govindachari TR, Pai BR, Ragade IS, Rajappa S, Viswanathan N (1961) Chemical examination of Tylophora asthmatica-V: structure of tylophorinine. Tetrahedron 14:288-295

Gujrati V, Patel N, Rao VN, Nandakumar K, Gouda TS, Shalam MD, Kumar SM (2007) Hepatoprotective activity of alcoholic and aqueous extract of leaves of Tylophora indica in rats. Indian J Pharmacol 39:43-47

Gupta S, George P, Gupta V (1979) Tylophora indica in bronchial asthma—a double blind study. Indian J Med Res 69:981-989

Gupta R, Datta A, Shri R (2012) Extraction process optimization of tylophorine from Tylophora asthmatica Wight \& Arn. Pharmacogn J 4:19-23

Haranath PS, Shayamalakumari S (1975) Experimental study on mode of action of Tylophora asthmatica in bronchial asthma. Indian J Med Res 63:661-670

Joa H, Blažević T, Grojer C, Zeller I, Heiss EH, Atanasov AG, Feldler I, Gruzdaitis P, Czaloun C, Proksch P, Messner B, Bernhard D, Dirsch VM (2019) Tylophorine reduces protein biosynthesis and rapidly decreases cyclin D1, inhibiting vascular smooth muscle cell proliferation in vitro and in organ culture. Phytomedicine 60:152938-152943

Kaur H, Anand M, Goyal D (2011) Extraction of tylophorine from in vitro raised plants of Tylophora indica. J Med Plants Res 5:729-734

Lee YZ, Huang CW, Yang CW, Hsu HY, Kang IJ, Chao YS, Chen IS, Chang HY, Lee SJ (2011) Isolation and biological activities of phenanthroindolizidine and septicine alkaloids from the Formosan Tylophora ovata. Planta Med 77:1932-1938

Meera R, Devi P, Muthumani P, Kameswari B, Eswarapriya B (2009) Evaluation of diuretic activity from Tylophora indica leaves extracts. J Pharm Sci Res 1:112-116

Mulchandani SB, Iyer SS, Badheka LP (1971) Structure of tylophorinindine a new potential antitumor alkaloid from Tylophora indica. Indian J Chem 19:505-506

Nayampalli SS, Sheth UK (1979) Evaluation of anti-allergic activity of Tylophora indica using rat lung perfusion. Indian J Pharmacol 11:229-232

Niphakis MJ, Gay BC, Hong KH, Bleeker NP, Georg GI (2012) Synthesis and evaluation of the anti-proliferative and NF- $\mathrm{\kappa B}$ activities of a library of simplified tylophorine analogs. Bioorg Med Chem 20:5893-5900

Oksman-Caldentey KM, Inzé D (2004) Plant cell factories in the post-genomic era: new ways to produce designer secondary metabolites. Trends Plant Sci 9:433-440

Pratama NP, Wulandari S, Nugroho AE, Fakhrudin N, Astuti P, Sudarsono (2018) Tylophorine abrogates G2/M arrest induced by doxorubicine and promotes increased apoptosis in T47D breast cancer cells. Asian Pac J Cancer Prev 19:3065-3069

Rao VK, Brook P (1970) Alkaloids of Tylophora indica and Tylophora dalzellii. US Patent 3:497-593

Rao KN, Venkatachalam SR (2000) Inhibition of dihydrofolate reductase and cell growth activity by the phenanthroindolizidine alkaloids pergularinine and tylophorinidine: the in vitro cytotoxicity of these plant alkaloids and their potential as antimicrobial and anticancer agents. Toxicol In Vitro 14:53-59

Rao AK, Gore KV, Guruswamy MN (1980) Physiological studies with Tylophora asthmatica in bronchial asthma. Indian J Med Res 71:144-148 
Rao KN, Bhattacharyya RK, Venkatachalam SR (1997) Inhibition of thymidylate synthase and cell growth by the phenanthroindolizidine alkaloids pergularinine and tylophorinidine. Chem-Biol Interact 106:201-211

Rao KN, Bhattacharyya RK, Venkatachalam SR (1998) Thymidylate synthase activity in leukocytes from patients with chronic myelocytic leukemia and acute lymphocytic leukemia and its inhibition by phenanthroindolizidine alkaloids pergularinine and tylophorinidine. Cancer Lett 128:183-188

Ratnagiriswaran AN, Venkatachalam K (1935) The chemical examination of Tylophora asthmat$i c a$ and isolation of the alkaloids tylophorine and tylophorinine. Indian J Med Res 22:433-441

Reddy BK, Balaji M, Reddy PU, Sailaja G, Vaidyanath K, Narasimha G (2009) Antifeedant and antimicrobial activity of Tylophora. Afr J Biochem Res 3:393-397

Saraswati S, Kanaujia PK, Kumar S, Kumar R, Alhaider AA (2013) Tylophorine, a phenanthraindolizidine alkaloid isolated from Tylophora indica exerts antiangiogenic and antitumor activity by targeting vascular endothelial growth factor receptor 2-mediated angiogenesis. Mol Cancer $12: 1-16$

Sasidharan N (2004) Biodiversity documentation for Kerala: flowering plants. Kerala Forest Research Institute, Peechi, p 293

Thomas TD (2006) Effect of gibberellic acid, sugars and abscisic acid on somatic embryogenesis in Tylophora indica (Burm. f.) Merrill. Chinese. J Biotechnol 22:465-471

Thomas TD (2009) Isolation, callus formation and plantlet regeneration from mesophyll protoplasts of Tylophora indica (Burm. f.) Merrill: an important medicinal plant. In Vitro Cell Dev Biol Plant 45:591-598

Thomas TD, Philip B (2005) Thidiazuron induced high frequency plant regeneration via organogenesis from leaf-derived calli of a medicinal climber, Tylophora indica (Burm. f.) Merrill. In Vitro Cell Dev Biol Plant 41:124-128

Udupa AL, Upupa SL, Guruswamy MN (1991) The possible site of antiasthmatic action of Tylophora asthmatica on pituitary adrenal axis in albino rats. Planta Med 57:409-413

Viswanathan N, Pai BR (1985) Alkaloids of Tylophora mollissima. J Nat Prod 48:997-998

Wang K, Hu Y, Liu Y, Mi N, Fan Z, Liu Y, Wang Q (2010a) Design, synthesis, and antiviral evaluation of phenanthrene-based tylophorine derivatives as potential antiviral agents. J Agric Food Chem 58:12337-12342

Wang Y, Gao W, Svitkin YV, Chen AP, Cheng YC (2010b) DCB-3503, a tylophorine analog, inhibits protein synthesis through a novel mechanism. PLoS One 5:1-11

Wang Y, Lee S, Ha Y, Lam W, Chen SR, Dutschman GE, Gullen EA, Grill SP, Cheng Y, Fürstner A, Francis S, Baker DC, Yang X, Lee KH, Cheng YC (2017) Tylophorine analogs allosterically regulates heat shock cognate protein 70 and inhibits hepatitis $C$ virus replication. Sci Rep $7: 1-10$

Wei L, Brossi A, Kendall R, Bastow KF, Morris-Natschke SL, Shi Q, Lee KH (2006) Antitumor agents 251: synthesis, cytotoxic evaluation, and structure-activity relationship studies of phenanthrene-based tylophorine derivatives (PBTs) as a new class of antitumor agents. Bioorg Med Chem 14:6560-6569

Wen T, Wang Z, Meng X, Wu M, Li Y, Wu X, Zhao L, Wang P, Yin Z, Li-Ling J, Wang Q (2014) Synthesis of novel tylophorine derivatives and evaluation of their anti-inflammatory activity. ACS Med Chem Lett 5:1027-1031

Yang CW, Chen WL, Wu PL, Tseng HY, Lee SJ (2009a) Anti-inflammatory mechanisms of phenanthroindolizidine alkaloids. Mol Pharmacol 69:749-758

Yang X, Shi Q, Liu YN, Zhao G, Bastow KF, Lin JC, Yang SC, Yang PC, Lee KH (2009b) Antitumor agents 268 design, synthesis and mechanistic studies of new 9-substituted phenanthrene-based tylophorine analogues as potent cytotoxic agents. J Med Chem 52:5262-5268

Yang CW, Lee YZ, Kang IJ, Barnard DL, Jan JT, Lin D, Huang CW, Yeh TK, Chao YS, Lee SJ (2010) Identification of phenanthroindolizines and phenanthroquinolizidines as novel potent 
anti-coronaviral agents for porcine enteropathogenic coronavirus transmissible gastroenteritis virus and human severe acute respiratory syndrome coronavirus. Antivir Res 88:160-168

Yang CW, Lee YZ, Hsu HY, Wu CM, Chang HY, Chao YS, Lee SJ (2013) c-Jun-mediated anticancer mechanisms of tylophorine. Carcinogenesis 34:1304-1314

You X, Pan M, Gao W, Shiah HS, Tao J, Zhang D, Koumpouras F, Wang S, Zhao H, Madri JA, Baker D, Cheng YC, Yin Z (2006) Effects of a novel tylophorine analog on collagen-induced arthritis through inhibition of the innate immune response. Arthritis Rheum 54:877-886

Zhen YY, Huang XS, Yu DQ, Yu SS (2002) Antitumor alkaloids isolated from Tylophora ovata. Acta Bot Sin 44:349-353 